\title{
50-70 yaş arası kişilerin kolorektal kanser risk faktörleri ve erken tanısına yönelik bilgi tutum ve davranışlarının değerlendirilmesi
}

\author{
Evaluation of knowledge, attitude and behavior for the colorectal cancer risk factors and \\ early diagnosis in persons between $50-70$ years
}

\author{
Sevda Yılmaz, Nilüfer Emre
}

\section{Öz}

Amaç: Bu çalışmada Pamukkale Üniversitesi Hastanesi Genel Cerrahi Polikliniği'ne başvuran 50-70 yaş arası kişilerin kolorektal kanser (KRK) belirti ve risk faktörlerine yönelik bilgilerini ve kolorektal kanser tarama testlerine yönelik bilgi, tutum ve davranışlarını değerlendirmek amaçlanmaktadır.

Gereç ve yöntem: Tanımlayıcı kesitsel tipte çalışma Ocak-Şubat 2021 tarihleri arasında genel cerrahi polikliniğine başvuran 50-70 yaş arası kişilerde yapıldı. Çalışmaya gönüllü katılan hastalara literatür taraması sonucunda oluşturulan kolorektal kanser tarama testleri, yapılma yerleri, yaptırma durumları, belirti ve risk faktörlerine yönelik sorulardan oluşan 38 maddelik anket formu yüz yüze görüşme tekniğiyle uygulandı. İstatistiksel olarak elde edilen veriler SPSS 21 programı kullanılarak analiz edildi. Verilerin değerlendirilmesinde tanımlayıcı istatistiksel yöntemler kullanıldı. Gruplar arasındaki ilişki ki-kare testi ile analiz edildi. İstatistiksel anlamlılık değeri $p<0,05$ olarak kabul edildi.

Bulgular: Çalışmaya 104 kişi dâhil edildi ve bunların yaş ortalaması 56,65 $\pm 6,42$ ve \%70,2'si (n=71) kadındı. Katılımcılar tarafından KRK için en sık bilinen belirtiler \%29,8 $(n=31)$ ile rektal kanama, \%26,9 ( $n=28)$ ile kabızlık iken, en sık bilinen risk faktörleri \%36,5 $(n=38)$ ailede kanser öyküsü ve $\% 21,2(n=22)$ ileri yaş olarak saptandı. Ayrıca katılımcıların sadece \%38,5'i $(n=40)$ kolonoskopiyi, \%27,9'u ( $n=29)$ GGK testini biliyordu. Yine katılımcıların sadece \%19,2'sinin ( $n=20)$ GGK testini, \%8,7'sinin $(n=9)$ kolonoskopi yaptırdığı tespit edildi. GGK testini yaptırmayanların ise \%38,5'nin ( $n=40)$ GGK testi ilgili bilgisi olmadığı ve \%15,4'ü $(n=16)$ hekim tarafından önerilmediği için yaptırmadığını bulundu.

Sonuç: Bu çalışma, araştırmaya katılan kişilerde KRK ve KRK tarama yöntemleri hakkında bilgi düzeyinin ve yaptırma oranının yetersiz olduğunu göstermektedir. Bu konudaki farkındalığı artırmak için çeşitli stratejilerin geliştirilmesine intiyaç vardır.

Anahtar kelimeler: Kolorektal kanser, risk, tarama testleri, bilgi, tutum.

Yılmaz S, Emre N. 50-70 yaş arası kişilerin kolorektal kanser risk faktörleri ve erken tanısına yönelik bilgi tutum ve davranışlarının değerlendirilmesi. Pam Tıp Derg 2021;14:726-733.

\begin{abstract}
Purpose: This study aimed to evaluate the knowledge about colorectal cancer (CRC) symptoms and risk factors, attitudes and behaviors towards colorectal cancer screening tests of people aged 50-70 who reffered to Pamukkale University Hospital general surgery outpatient clinic.

Material and methods: A descriptive cross-sectional study was conducted on people aged 50-70 years who reffered to the general surgery outpatient clinic between January and February 2021. A 38-item questionnaire consisting of questions about colorectal cancer screening tests, application locations, conditions, symptoms and risk factors, which was created as a result of the literature review, was applied to the patients who participated in the study voluntarily using the face-to-face interview technique. Data obtained were analyzed statistically using SPSS 21 software. Descriptive statistical methods were used to evaluate the data. The relations amongst groups were analyzed by chi-square tests. Statistical significance level accepted was to be $p<0.05$

Results: 104 people were included in the study and their mean age was $56.65 \pm 6.42$ and $70.2 \%(n=71)$ of them were women. The most common symptoms for CRC by the participants were rectal bleeding with $29.8 \%$ $(n=31)$, constipation with $26.9 \%(n=28)$, while the most common risk factors were $36.5 \%(n=38)$ a family history of cancer and $21.2 \%(n=22)$ of advanced age. In addition, only $38.5 \%(n=40)$ of the participants knew about colonoscopy, $27.9 \%(n=29)$ of them knew the fecal occult blood testing (FOBT). Again, it was found that only $19.2 \%(n=20)$ of the participants had the FOBT and $8.7 \%(n=9)$ had a colonoscopy. It was seen that $38.5 \%$ $(n=40)$ of those who did not have FOBT did not have knowledge about the FOBT and $15.4 \%(n=16)$ did not have it because it was not recommended by the physician.

Conclusion: This study shows that the level of knowledge about CRC and CRC screening methods and the rate of getting it done is insufficient for the participants. Various strategies are needed to increase awareness on this issue.
\end{abstract}

Sevda Yılmaz, Dr. Öğr. Üye. Pamukkale Üniversitesi Tıp Fakültesi, Genel Cerrahi Anabilim, Denizli, Türkiye, e-posta: syilmaz_md@hotmail.com (https://orcid.org/0000-0002-1309-0805) (Sorumlu Yazar)

Nilüfer Emre, Dr. Öğr. Üye. Pamukkale Üniversitesi Tıp Fakültesi Aile Hekimliği Anabilim, Denizli, Türkiye, e-posta: nilemre83@gmail.com (https://orcid.org/0000-0002-6519-0920) 
Key words: Colorectal cancer, risk, screening tests, knowledge, attitude.

Yilmaz S, Emre N. Evaluation of knowledge, attitude and behaiıor for the colorectal cancer risk factors and early diagnosıs in persons between 50-70 years. Pam Med J 2021;14:726-733.

\section{Giriş}

Kolorektal kanser (KRK) tüm Dünyada erkekler arasında görülen üçüncü ve kadınlar arasında ikinci sırada en sık görülen kanser türüdür. Uluslararası Kanser Araştırma Ajansı (IARC), 2018'de kolorektal kanser ile ilgili 1,8 milyon yeni vaka ve 0,8 milyon ölüm bildirmiştir $[1,2]$. Ülkemizede ise KRK erkeklerde 4., kadınlarda 3. sırada en sık görülen kanserdir [3].

KRK etiyolojisinde genetik ve çevresel faktörler sorumlu tutulmaktadır ve vakaların büyük çoğunluğunu sporadik KRK'ler oluşturmaktadır [4].

Yaşam tarzıyla ilgili birçok faktör, kolorektal kanser ile ilişkilendirilmiştir. Kolorektal kanser ile ilişkilendirilen başıca faktörler tütün kullanımı, alkol tüketimi, fiziksel hareketsizlik, diyet ve obezitedir. Aslında, diyet, kilo ve egzersiz ile kolorektal kanser riski arasındaki bağlantılar, herhangi bir kanser türü için en güçlü olanlardan bazılarıdır [5].

Kolorektal kanserlerin yaklaşık \%25'i çekum ve çıkan kolon, \%25'i rektum ve sigmoid kolon, $\% 25$ 'i ise inen kolon ve sigmoid kolonda görülürler [6]. Klinik bulgularda yerleşim yeri ile ilişkili olarak sağ kolon tümörlerinde karın ağrısı, halsizlik, kilo kaybı ve kronik kan kaybına bağlı demiri eksikliği anemisi belirtileri daha çok görülür. Sol kolon tümörlerinde ise dışkılama alışkanlıklarında değişiklikler ve bulantı, kusma gibi kolon tıkanıklığı belirtileri daha sık görülmektedir [7].

KRK tarama yöntemleri ile erken evrede saptanabilen kanserlerdendir. $\mathrm{Bu}$ nedenle erken tanı, tedavi başarısında ve sağkalımda en önemli noktadır. Ayrıca tarama programları ile henüz invaziv bir kanser oluşturmamış premalign lezyonlar da saptananbileceği için riskli hastalarda bir kat daha önemlidir [8]. Ülkemizde kolorektal kanser tarama programı ilk kez 2009 yılında sağlık bakanlığınca belirlenmiş ve 2012 yılından bu yana 50-70 yaş arası sağılılı bireylere 2 yılda bir gaitada gizli kan testi (GGT) ve 10 yılda bir kolonoskopi yapılması şeklinde uygulanmaktadır [8]. GGK testi gaitada bulunan hemoglobini peroksidaz reaksiyonu ile açığa çıkaran bir testtir, basit ve uygulanabilir olması nedeniyle birinci basamakta da kolaylıkla uygulanabilir bir yöntemdir $[9,10]$. Kolonoskopi ile kolon mukozası direkt olarak görülebilidiği gibi işlem sırasında biyopsi alınması, polip ve lokal tümörlerin eksizyonunun yapılabilmesi gibi avantajları da mevcuttur [11]. Kolonoskopi KRK tanı ve taramasında en etkili yöntemidir [12].

KRK tarama programlarını batı toplumlarında yaşayan insanlar yaygın olarak yaptırmasına rağmen ülkemizde tarama programlarına katııım oranı düşüktür. Bu duruma KRK ile ilgili bilgi eksikliğinin olması, doğru olmayan bilgi ve tutumların sebep olduğu ön görülmektedir [13].

Bu çalışmanın amacı; 50-70 yaş arası kişilerin kolorektal kanser belirti ve risk faktörlerine yönelik bilgilerini ve kolorektal kanser tarama testlerine yönelik bilgi, tutum ve davranışlarını değerlendirmektir.

\section{Gereç ve yöntem}

Çalışma tanımlayıcı kesitsel tipte tasarlandı. Çalışma öncesi Pamukkale Üniversitesi Tıp Fakültesi Girişimsel Olmayan Klinik Araştırmalar Etik Kurulu'ndan 05.01.2021 tarih ve E-60116787-020-4279 sayılı onay alındı. Araştırmaya 2021 Ocak-Şubat tarihleri arasında Genel cerrahi polikliniklerine başvuran, araştırmamıza gönüllü katılmayı kabul eden, 50-70 yaş arası, kolorektal kanser ve kolon polip tanısı olmayan hastalar dahil edidi. Çalışmaya katılanlara demografik özellikler, fiziksel aktivite durumu, sigara ve alkol kullanımı, kendisinde ve ailesinde kanser öyküsü, sağlık kuruluşlarına başvuru sıklıkları ile, literatür taraması sonucunda oluşturulan kolorektal kanser tarama testleri, yapılma yerleri, yaptırma durumları, belirti ve risk faktörlerine yönelik sorulardan oluşan 38 maddelik anket formu yüz yüze görüşsme tekniğiyle uygulandı.

Veriler SPSS 21.0 (Statistical Package For Social Sciences) paket programıla analiz edildi. Sürekli değişkenler ortalama \pm standart sapma ve kategorik değişkenler sayı ve yüzde 
olarak verildi. Kategorik değişkenler arasındaki farklılıklar ise Ki kare ve Fisher Exact test analizi ile incelendi. İstatistiksel anlamlılık düzeyi $p<0,05$ olarak alındı.

\section{Bulgular}

Çalışmaya katılan 104 kişinin yaş ortalaması $56,65 \pm 6,42$ ve $\% 70,2$ 'si $(n=71)$ kadındı.
Katılımcıların demografik özellikleri Tablo 1'de, kolon kanseri belirtileri ve risk faktörlerine ilişkin bilgileri Tablo 2'de yer almaktadır.

Kolon kanseri tarama testlerinden katılımcıların \%54,8'i ( $n=57)$ hiçbir tarama testini bilemezken, \%38,5'i (n=40) kolonoskopiyi, \%27,9'u (n=29) GGK testini, \%19,2'si ( $n=20)$ Bilgisayarlı tomografi ve \%9,6'sı $(n=10)$

Tablo 1. Katılımcıların demografik özellikleri

\begin{tabular}{|c|c|c|}
\hline & $\mathbf{n}$ & $\%$ \\
\hline \multicolumn{3}{|l|}{ Cinsiyet } \\
\hline Kadın & 73 & 70,2 \\
\hline Erkek & 31 & 29,8 \\
\hline \multicolumn{3}{|l|}{ Вмі } \\
\hline $18,5-24,99$ & 18 & 17,3 \\
\hline $25,00-29,99$ & 53 & 51,0 \\
\hline$\geq 30,00$ & 33 & 31,7 \\
\hline \multicolumn{3}{|l|}{ Medeni durum } \\
\hline Evli & 93 & 89,4 \\
\hline Bekar & 11 & 10,6 \\
\hline \multicolumn{3}{|l|}{ Eğitim durumu } \\
\hline İlkokul ve altı & 48 & 46,1 \\
\hline Ortaokul & 14 & 13,5 \\
\hline Lise & 18 & 17,3 \\
\hline Üniversite & 24 & 23,1 \\
\hline \multicolumn{3}{|l|}{ Gelir durumu } \\
\hline Asgari ücret ve altı & 54 & 51,9 \\
\hline Asgari ücret üzeri & 50 & 48,0 \\
\hline \multicolumn{3}{|l|}{ Yaşadığı yer } \\
\hline Kırsal bölge & 40 & 38,4 \\
\hline Kentsel bölge & 64 & 61,5 \\
\hline \multicolumn{3}{|l|}{ Kronik hastalık } \\
\hline Evet & 52 & 50,0 \\
\hline Hayır & 52 & 50,0 \\
\hline \multicolumn{3}{|l|}{ Sigara içme } \\
\hline Evet & 26 & 25,0 \\
\hline Hayır & 78 & 75,0 \\
\hline \multicolumn{3}{|c|}{ Ailede kanser öyküsü } \\
\hline Evet & 32 & 30,8 \\
\hline Hayır & 72 & 69,2 \\
\hline \multicolumn{3}{|c|}{ Egzersiz yapma durumu } \\
\hline Evet & 58 & 55,8 \\
\hline Hayır & 46 & 44,2 \\
\hline \multicolumn{3}{|c|}{ Sağlık kuruluşuna başvuru sıklığı } \\
\hline$\leq$ Yılda bir & 36 & 34,6 \\
\hline Yılda 3-4 kez & 45 & 43,3 \\
\hline Ayda 1 ve daha sık & 23 & 22,1 \\
\hline \multicolumn{3}{|c|}{ Tarama testi bilgi kaynakları } \\
\hline Televizyon/radyo & 28 & 26,9 \\
\hline Kitap/dergi & 7 & 6,7 \\
\hline Sağlık personeli & 39 & 37,5 \\
\hline Aile/akraba & 9 & 8,7 \\
\hline İnternet & 26 & 25,0 \\
\hline
\end{tabular}


Tablo 2. Katılımcıların Kolon kanseri belirtileri ve risk faktörlerine ilişkin bilgileri

\begin{tabular}{llllll}
\hline Belirtiler & $\mathbf{n}$ & $\mathbf{\%}$ & Risk faktörleri $^{*}$ & $\mathbf{n}$ & \% \\
\hline Bilmiyorum & 58 & 55,8 & Bilmiyorum & 52 & 50,0 \\
Rektal kanama & 31 & 29,8 & Ailede kanser öyküsü & 38 & 36,5 \\
Kabızlık & 28 & 26,9 & Illeri yaş & 22 & 21,2 \\
Kilo kaybı & 19 & 18,3 & Bağırsakta polip & 20 & 19,2 \\
Anemi & 18 & 17,3 & Kronik barsak hastalığı & 20 & 19,2 \\
Dışkılama alışkanlıklarında değişiklik & 14 & 13,5 & Obezite & 14 & 13,5 \\
İshal & 8 & 7,7 & Fiziksel aktivie azlığı & 9 & 8,7 \\
& & & Kişide kanser öyküsü & 7 & 6,7 \\
\hline
\end{tabular}

*Birden fazla şık işaretlenmiştir

sigmoidoskopiyi bildiği saptandı. Kolon kanseri tarama testleri bilme oranı; eğitim seviyesi yükseldikçe artıyordu ve kentsel bölgede yaşayanlarda kırsal bölgede yaşayanlara göre, asgari ücret üzerinde geliri olanlarda asgari ücret ve altında gelir sahibi olanlara göre ve düzenli fiziksel aktivite yapanlarda yapmayanlara göre istatiksel olarak anlamlı düzeyde daha yüksek bulundu ( $p=0,000, p=0,040, p=0,004, p=0,022)$.

Kolon kanseri tarama testlerinin hangi yaş aralığında olduğu sorulduğunda; katılımcıların sadece \%24,0'ü ( $n=25)$ 50-70 yaş arasında olduğunu belirtti. Tarama testlerinin yaş aralığını doğru bilme durumu, kentsel bölgede yaşayanlarda kırsal bölgede yaşayanlara göre istatistiksel olarak anlamlı oranda yüksekti $(p=0,008)$.

Kolon kanseri tarama testlerinden GGK testinin nerede ve ne sıklıkla yapıldığı sorulduğunda; \%46,2 ( $\mathrm{n=48)}$ kişi testin hangi merkezlerde yapıldığını biliyor, \%7,7 $(n=8)$ kişide yaptırma sıklığını doğru olarak biliyordu. Katılımcıların GGK testinin yapıldığı yeri bilme durumu ile demografik özellikler arasında anlamlı fark bulunmadı. Ancak GGK testi yaptırma sıklığını bilme oranı; eğitim seviyesi artışı ile, kentsel bölgede yaşayanlarda kırsal bölgede yaşayanlara göre, düzenli fiziksel aktivite yapanlarda yapmayanlara göre istatistiksel olarak anlamlı düzeyde daha fazla bulundu ( $p=0,018, p=0,022, p=0,008)$.

Kolonoskopi tarama sıklığını ise $\% 12,5$ ( $n=13)$ kişi doğru biliyordu. Kolonoskopi sıklığını bilme oranı eğitim düzeyi arttıkça artıyor ve gelir düzeyi asgari ücret üzerinde olanlarda asgari ücret ve altında olanlara göre istatistiksel olarak anlamlı düzeyde daha fazla bulundu $(p=0,032$, $p=0,037$ )
"Kolon kanseri kişinin beslenme tarzı ile ilişkili midir?" sorusuna katılımcıların \%57,7'si $(n=60)$ evet, \%6,7'si $(n=7)$ hayır ve \%35,7'si de $(n=37)$ bilmiyorum olarak cevaplamaktadır. Katılımcılardan üniversite mezunu olan, asgari ücret üzerinde geliri olan ve kentsel bölgede yaşayanlar istatistiksel olarak daha yüksek oranda beslenme tarzının kolon kanseri üzerine etkisi olduğunu belirtmekteydi ( $p=0,000$, $p=0,019, p=0,003)$. Ayrıca kolon kanseri tarama testlerini, GGK tarama yaş aralığını ve GGK tarama sıklığını bilenlerin bilmeyenlere göre kolon kanserinin beslenme ile ilişkili olduğunu belirtmeleri istatistiksel olarak anlamlı farklılık göstermekteydi ( $p=0,000, p=0,046, p=0,042)$. Yine tarama testlerinin erken tanı sağladığını belirtenler beslenme tarzı ile de ilişkili olduğunu daha yüksek oranda belirtmekteydi $(p=0,000)$.

Katılımcıların \%19,2'sinin $\quad(n=20) \quad$ GGK testini, \%8,7'sinin ( $n=9)$ kolonoskopi yaptırdığı tespit edildi Tablo 3'te GGK testi yaptırmama nedenleri yer almaktadır. Demografik özelliklerden sadece düzenli fiziksel aktivite yapanların yapmayanlara göre GGK testini yaptırma oranı istatistiksel olarak anlamlı farklılık göstermekteydi $(p=0,023)$. Yine kolon kanseri tarama testlerini, GGK testi sıklık ve nerede yapıldığını bilenlerde GGK testini yaptırma durumunu istatistiksel olarak anlamlı oranda daha yüksekti $(p=0,000, p=0,001, p=0,000)$.

Katılımcılara kolon kanseri ve tarama testleri hakkında eğitim almayı isteme durumları sorulduğunda; \%55,8 ( $n=58)$ kişi eğitim almak istediklerini belirtirken, \%44,2 $(n=46)$ kişi herhangi bir eğitim almak istemediğini belirtti. Kişilerin eğitim düzeyi yüksekliği ile ve düzenli fiziksel aktivite yapma durumu ile kolon kanseri ve tarama testleri hakkında eğitim almayı isteme anlamlı farklılık göstermekteydi $(p=0,016$, $p=0,001$ ). 
Tablo 3. Katılımcıların GGK yaptırmama nedenleri

\begin{tabular}{lll}
\hline & $\mathbf{n}$ & $\mathbf{\%}$ \\
\hline GGk testi yaptırmakla ilgili bilgisi yok & 40 & 38,5 \\
Hekim tarafından önerilmediği için & 16 & 15,4 \\
Herhangi bir şikayeti olmadığından & 11 & 10,6 \\
Olumsuz sonuçtan korktuğu için & 8 & 7,7 \\
Rahatsız olacağını düşünme & 6 & 5,8 \\
Yaptırmak istememe & 3 & 2,9 \\
Kanser riski olmadığı için & 2 & 1,9 \\
*Birden fazla şık işaretlenmiştir & &
\end{tabular}

\section{Tartışma}

Kolorektal kanser tanısı ve KRK'e bağı ölüm oranları son yıllarda giderek artış göstermektedir. Gelişmiş ülkelerde bu artışın sebebi yaşı nüfusun artması, diyet alışkanlıklarında batııılaşma ve hazır gıda kullanımının artışı, sigara içme, fiziksel aktivitede azalma ve obezite gibi risk faktörlerine bağlanmaktadır [14]. Yeni tedavi modaliteleri ve agresif tedavi yaklaşımlarının kür oranları ve uzun süreli sağkalım üzerine etkisi sınırıdır. KRK'in uzun süreden beri polipoid bir öncülden geliştiği kabul edildiği için tarama programları bu anlamda çok önemlidir [14]. Etkin tarama yöntemlerinin uygulanması ile KRK sıklığı ve ölüm oranlarının azalacağı yapılan çalışmalarda bildirilmektedir [15]. Bizim çalışmamızda kişilerin kolorektal kanser risk faktörleri ve erken tanısına yönelik bilgi tutum ve davranışları değerlendirilmiş ve KRK bilgi durumlarının yetersiz olduğu ve tarama programlarına düşük oranda katıldıkları saptanmıştır.

Çalışmamızda hastalarımızın \%57'sinin beslenme tarzının KRK için bir risk faktörü olduğunu bildikleri görülmektedir, bu durum özellikle şehirde yaşayan, eğitim seviyesi ve gelir durumu yüksek olan hastalar arasında daha fazla saptanmıştır. Yapılan bir çalışmada katılımcıların \%35,9'unun beslenme alışkanlıklarının KRK için bir risk faktörü olduğunu bildiğini göstermektedir [16]. AsyaPasifik ülkelerinde yapılan çok merkezli bir çalışmada ise katılımcıların en fazla bildikleri risk faktörlerinin kızartılmış besin tüketmek, sebze ve meyveden fakir beslenmek ve aile öyküsü olduğu görülmektedir [17].

Çalışmamızda katııımcıların yarısının KRK risk faktörlerini bilmediklerini, bilenler arasında ise en fazla bilinen risk faktörünün KRK'li aile öyküsünün olduğu görüldü. Literatürde yapılan çalışmalarda da aile öyküsünün en fazla bilinen risk faktörü olduğu görülmektedir [16, 18].

Çalışmamızda katılımcıların yarıdan fazlasnını KRK belirtilerini bilmedikleri ve bilenler arasında dışkıda kan saptanması \%29,8 ve kabızlık \%28 ile en fazla bilinen belirtiler olduğu görüldü. Yapılan bir araştırmada KRK için önemli bir belirti olan dışkılama alışkanlıklarındaki değişiklikler katılımcıların hiçbiri tarafından bilinememiş [19], bir başka araştırmada ise katılımcıların \%48'i dışkılama alışkanlıklarında değişikli ve \%55'i dışkıda kan saptanmasının en sık görülen belirtiler olduğunu belirtmişlerdir [17].

Çalışmamıza katılanların \%54'8'inin KRK tarama testlerinden hiçbir tarama testini bilmediği ve bilenler arasında kolonoskopinin \%38 ila ensık bilinen tarama testi olduğu görülmüştür. Çalışmamızda KRK tarama testlerini bilme oranının eğitim ve gelir seviyesi ile arttığı, kentsel bölgelerde yaşayanlarda ve düzenli fiziksel aktivitede bulunanlarda daha daha fazla bilindiği görülmüştür. Ülkemizden yapılan bir çalışmada Katılımcıların \%56,2'sinin KRK tarama testleri hakkında bilgi sahibi oldukları görülürken [20], başka bir çalışmada ise bu oranın \%6,2 ile oldukça düşük olduğu görülmektedir [19].

Avustralya'dan bildirilen bir çalışmada bireylerin \%78'inin KRK tarama testlerini duyduğu ama sadece \%15'inin doğru bir şekilde tanımladığı bildirilmektedir [18]. İngiltereden bildirilen bir çalışmada ise KRK tarama testlerini katılımcıların \%93,9'unun duyduğu bildirilmektedir [21].

Çalışmamızda katıımcıların \%24'ünün KRK tarama testlerinin yapıldığı yaş aralığını doğru bildikleri görülmüş ve tarama testlerinin yaş 
aralığını doğru bilme durumunun kentsel bölgede yaşayanlarda daha yüksek olduğu saptanmıştır. $\mathrm{Bu}$ durum kentsel bölgelerde yaşayanlarda medya ve duyurular ile bilgilendirmelerin daha fazla olması neticesinde olmuş olabilir. Nitekim çalışmamızda katılımcıların KRK taramaları ile ilgili bilgi edinme kaynaklarının büyük oranda medya ve internet üzerinden olması bu bulguyu desteklemektedir. Ülkemizde Aydın bölgesinde yapılan bir çalışmada katılımcıların \%17,2'sinin 50 yaş üstü kişilere KRK taraması yapılması gerektiğini bildirdikleri görülmektedir. Bu çalışmada katılımcıların \%28,3'ünün sağlık çalışanlarından bilgi edindiği, \%70 oranında medya ve arkadaş çevresinden bilgi edindikleri görülmektedir [19].

Çalışmamızda katılımcıların \%46,2'sinin GGK testinin hangi merkezde yapıldığını ve sadece \%7,7'sinin ne sıklıkta yapıldığını doğru bildikleri görülmüştür. GGK testini yaptırma sıklığını bilme durumlarının eğitim seviyesi yüksek, kentsel bölgelerde yaşayan ve düzenli fiziksel aktivite yapanlar arasında daha fazla olduğu görülmektedir. Ülkemizde 3. Basamak bir sağlık merkezine başvuranlar arasında yapılan bir çalışmada katılımcıların \%14,8'inin GGK testini, \%56,5'inin rektosigmoidoskopi ve kolonoskopi tetkikini, \%15,2'sinin tomografiyi duyduğu, ancak \%13,5'inin bu yöntemleri duymasına rağmen yöntemler hakkında bir fikrinin olmadığı görülmüştür [20]. Ankarada yapılan bir çalışmada ise katılımcıların \%80,6'sının GGK testini duyduğunu göstermektedir [16]. 50-74 yaş grubu 1013 katılımcının değerlendirildiği bir çalışmada ise katılımcıların GGK testini duyma oranları $\% 48$, kolonoskopi tetkikini duyma oranları ise 35,3 saptanmıştır [22]. Bizim çalışmamızda katılımcıların \%12,5'inin kolonoskopi tetkikini doğru bildikleri ve \%8,7'sinin kolonoskopi yaptırdığı saptanmıştır. Çalışmamızda kolonoskopiyi bilme durumlarının eğitim düzeyi ve gelir düzeyi yüksek olanlar arasında daha fazla olduğu görülmektedir.

Çalışmamıza katılanların sadece \%19,2'sinin GGK testi yaptırdığı ve yaptırmayanların \%38,5'inin GGK testi ile ilgili bilgisi olmadığı için yaptırmadıklarını göstermektedir. Kanadanın tüm eyaletlerinde yapılan geniş volümlü bir çalışmada kolorektal kanser tarama oranı $\% 55,2$, GGK testi yaptırma oranı \%30, kolonoskoi ve/ veya sigmoidoskopi yaptırma oranı ise \%37 saptanmıştır [23]. Amerika'da 50-74 yaş grubu kişilerde yapılan bir çalışmada GGK testi oranı $\% 38$, herhangi bir KRK tarama testi yaptırma oranı \%66 saptanmıştır [22]. Ülkemizde yapılan çalışmalarda bizim çalışmamızla benzer şekilde KRK tarama testi yaptırma oranları oldukça düşüktür. Ege Üniversitesi Tıp Fakültesi refakatçileri arasında yapılan bir çalışmada katılımcıların \%94'ünün son 10 yıl içinde bir tarama testi yaptırmadıkları bildirilmiştir [24]. 3. Basamak bir sağlık merkezine başvuran 5070 yaş grubu kişilerde katılımcıların sadece \%18,3'üne herhangi bir KRK tarama testi yapıldığı, yapılanlar arasında ise $\% 77$ ile GGK testinin en fazla yapılan yöntem olduğu görülmüştür [20].

Çalışmamızda katılımcıların \%55,8'inin KRK ve tarama testleri hakkında eğitim almak istedikleri görülmektedir. Özellikle eğitim düzeyi yüksek ve düzenli fiziksel aktivite yapanlar arasında bu durumun daha fazla olduğu görülmektedir. Çalışmamızda tarama testlerini yaptırmamama nedenlerinin başında kişilerin testlerle ilgili bilgisinin olmaması ve doktor tarafından önerilmediği için yapılmadığı görülmektedir. Aydın bölgesinde yapılan bir çalışmada da çalışmamızla benzer şekilde kişilerin bilgi eksikliği ve doktor tavsiyesi olmadığı için tarama yaptırmadıkları görülmüş ve tarama yaptırmanın önündeki en büyük engelin bilgi eksikliği ve bu nedenle kişinin kendini risk altında görmemesi olarak saptanmıştır [19].

Araştırmamızın tek bir şehirde, 3. Basamak bir hastanede ve sınırlı sayıda bireyle yapılması ve bu nedenle topluma genellenememesi kısıtlılıkları arasındadır. Ancak çalışmamız yüz yüze görüşme şeklinde yapılarak kişilerin kolon kanseri ve tarama testleri hakkındaki farkındalıklarını da arttırır niteliktedir.

Sonuç olarak, çalışmamıza katılanlar arasında KRK ve KRK tarama yöntemleri ile ilgili bilgi düzeylerinin ve yaptırma oranlarının yetersiz olduğu ve bilgisi olanların da daha çok sağlık çalışanları, internet ve medya üzerinden bilgi edindikleri görülmüştür. $\mathrm{Bu}$ nedenle sağlık çalışanları olarak KRK tarama programları hakkında bilgilendirmeler yaparak ve medyayı etkin ve doğru kullanarak kişilerin bilgi düzeylerinin arttırılabileceği görüşündeyiz.

Çıkar ilişkisi: Yazarlar çıkar çatışması olmadığını bildirmişlerdir. 


\section{Kaynaklar}

1. El Kinany K, Huybrechts I, Kampman E, et al. Concordance with the World Cancer Research Fund/American Institute for Cancer Research recommendations for cancer prevention and colorectal cancer risk in Morocco: a large, population-based case-control study. Int J Cancer 2019;145:1829-1837. https://doi.org/10.1002/ijc.32263

2. Colorectal cancer statistics. World Cancer Research Fund 2018. Available at: https://www.wcrf.org/ dietandcancer/cancer-trends/colorectal-cancerstatistics. Accessed April 13, 2021

3. Özdoğan M. Türkiye Kanser İstatistikleri 2020. Erişim adresi: https://www.drozdogan.com/turkiye-kanseristatistikleri-2020/. Erişim tarihi 13 Nisan 2021

4. Vasen HF, Watson P, Mecklin JP, Lynch HT. New clinical criteria for hereditary nonpolyposis colorectal cancer (HNPCC, Lynch syndrome) proposed by the International Collaborative group on HNPCC. Gastroenterology 1999;116:1453-1456. https://doi. org/10.1016/s0016-5085(99)70510-x

5. Colorectal cancer causes, risk factors, and prevention. Available at: https://www.cancer.org/content/dam/ CRC/PDF/Public/8605.00.pdf. Accessed April 13, 2021

6. Robbins Temel Patoloji Kumar Abbas Fausto Mitchell 8. Basım, Bölüm 15, Kolorektal Karsinomlar, 2008:623624.

7. Değerli Ü, Erbil Y. Kolon kanseri. Cerrahi Gastroenteroloji. Nobel Tıp Kitabevleri, 2005:191-198.

8. Kolorektal kanser tarama programı ulusal standartları. Erişim adresi: https://hsgm.saglik.gov.tr/tr/kansertarama-standartlari/listesi/kolorektal-kanser-taramaprogram\%C4\%B1-ulusal-standartlar\%C4\%B1.html. Erişim tarihi 23 Nisan 2021

9. Issa IA, Noureddine M. Colorectal cancer screening: an updated review of the available options. World J Gastroenterol 2017;23:5086-5096. https://doi. org/10.3748/wjg.v23.i28.5086

10. Nadel MR, Shapiro JA, Klabunde $\mathrm{CN}$, et al. A national survey of primary care physicians' methods for screening for fecal occult blood. Ann Intern Med 2005;142:86-94. https://doi.org/10.7326/0003-4819142-2-200501180-00007

11. Rex DK, Johnson DA, Anderson JC, Schoenfeld PS, Burke CA, Inadomi JM, American College of Gastroenterology guidelines for colorectal cancer screening 2009 [corrected]. Am J Gastroenterol 2009;104:739-750. https://doi.org/10.1038/ ajg.2009.104

12. Sonnenberg A, Delcò F, Inadomi JM. Cost-effectiveness of colonoscopy in screening for colorectal cancer. Ann Intern Med 2000;133:573-584. Available at: https:// www.acpjournals.org/doi/10.7326/0003-4819-133-8200010170-00007. Accessed May 08, 2021
13. Genç Z, Yalçinöz Baysal H. Birinci basamağa başvuran bireylerin kolorektal kansere yönelik sağlık inançlarının gaitada gizli kan testi yaptırma durumlarına etkisi. Sağlık ve Toplum. 2020;30:90-97. Erişim adresi: https:// app.trdizin.gov.tr/makale/TXpnM05qTXhNUT09/ birinci-basamaga-basvuran-bireylerin-kolorektalkansere-yonelik-saglik-inanclarinin-gaitada-gizli-kantesti-yaptirma-durumlarina-etkisi. Erişim tarihi 09 Mayıs 2021

14. Kuipers EJ, Grady WM, Lieberman D, et al. Colorectal cancer. Nat Rev Dis Primer 2015;1:15065. https://doi. org/10.1038/nrdp.2015.65

15. Lieberman D. Kolon kanseri tarama ve izleme tartışmaları. Curr Opin Gastroenterol 2009;2:265-272. Erişim adresi: https://www.turkiyeklinikleri.com/article/ tr-kolon-kanseri-tarama-ve-izleme-tartismalari-56581. html. Erişim tarihi 23 Nisan 2021

16. Vaïzoğlu Acar S, Turhan T, Temel F, et al. Birinci basamakta 50 yaş ve üzeri bireylerde kolorektal kanser ile ilişkili olabilecek bazı faktörlerin ve gaitada gizli kan tetkikine uyumun değerlendirilmesi. Türk Geriatri Derg 2010;13:79-86. Erişim adresi: https://app.trdizin.gov. tr/makale/TVRFNE9ERXINZz09/birinci-basamakta50-yas-ve-uzeri-bireylerde-kolorektal-kanser-ile-iliskiliolabilecek-bazi-faktorlerin-ve. Erişim tarihi 18 Mayıs 2009

17. Koo JH, Arasaratnam MM, Liu K, et al. Knowledge, perception and practices of colorectal cancer screening in an ethnically diverse population. Cancer Epidemiol 2010;34:604-610. https://doi.org/10.1016/j. canep.2010.05.013

18. Christou A, Thompson SC. Colorectal cancer screening knowledge, attitudes and behavioural intention among Indigenous Western Australians. BMC Public Health 2012;12:528. https://doi.org/10.1186/1471-2458-12528

19. Şahïn NŞ, Üner BA, Aydin M, ve ark. Aydın merkez ilçede kolorektal kanser taramasına ilişkin bilgi, tutum ve engeller. Türkiye Aile Hekim Derg 2015;19:37-48.

20. Pirincci S, Benli C, Okyay P. Patients admitted to tertiary health care center colorectal cancer screening program awareness study. TAF Prev Med Bull 2015;14:209-214. https://doi.org/10.5455/pmb.1-1398327138

21. Ritvo P, Myers RE, Paszat L, Serenity M, Perez DF, Rabeneck L. Gender differences in attitudes impeding colorectal cancer screening. BMC Public Health 2013;13:500. https://doi.org/10.1186/1471-2458-13500

22. Walsh JME, Salazar R, Kaplan C, Nguyen L, Hwang J, Pasick RJ. Healthy colon, healthy life (colon sano, vida sana): colorectal cancer screening among Latinos in Santa Clara, California. J Cancer Educ 2010;25:36-42. https://doi.org/10.1007/s13187-009-0007-z 
23. Singh $H$, Bernstein $C N$, Samadder JN, Ahmed R. Screening rates for colorectal cancer in Canada: a cross-sectional study. CMAJ Open 2015;3:149157. https://doi.org/10.9778/cmajo.20140073

24. Eşer I, Khorshid L, Güneş ÜY, Zaybak A. Sağlıklı bireylerde kanser risk faktörleri. E.Ü. Hemşirelik Yüksek Okulu Derg 2007;23:13-22.

Teşekkür: Katkılarından dolayı Aslı Sıla Aydınlık, Illknur Kocaman, Havva Şevval Şenol ve Rabia Ay'a teşekkür ederiz.

Etik onayı: Pamukkale Üniversitesi Tıp Fakültesi Girişimsel Olmayan Klinik Araştırmalar Etik Kurulu'ndan 22/12/2020 tarih ve 01 sayılı kurul kararıyla onay alınmıştır.

\section{Yazarların makaleye olan katkıları}

S.Y.veN.E. çalışmanınana fikrinive hipotezini kurgulamışlardır. Teoriyi geliştirmiş, gereç ve yöntem bölümünü düzenlemişlerdir. Sonuçlar kısmınındaki verilerin değerlendirmesini yapmışlardır. Makalenin tartışma bölümü S.Y. ve N.E. tarafından yazılmış, S.Y. ve N.Y. gözden geçirip gerekli düzeltmeleri yapmış ve onaylamıştır. Ayrıca yazarlar çalışmanın tamamını tartışmış ve son halini onaylamıştır. 